\title{
Pensamiento y fragmento. A propósito de Lichtenberg, Nietzsche y Adorno
}

\author{
LUCIANO ESPINOSA RUBIO \\ Universidad de Salamanca
}

El presente estudio se ocupa de las relaciones entre la forma y el fondo del discurso filosófico; más exactamente, de las implicaciones y consecuencias del texto fragmentario, tanto en sentido teórico como práctico. De manera concreta, el comentario de Lichtenberg, Nietzsche y Adorno permite rastrear en autores de una misma tradición cultural ciertos elementos de continuidad a través de pers- pectivas históricas y enfoques diferentes. Puede decirse que en este conjunto el pensamiento en forma fragmentaria sirve para una crítica general de la modernidad desde posiciones distintas, pero también complementarias. Por último, se ofrece un boceto de lo que puede ser una teoría compleja del fragmento.

\section{Introducción}

Ante todo, hay que recordar la gran riqueza y pluralidad de expresiones filosóficas que la historia nos regala: poema, diálogo, tratado, exhortación o epistola, confesiones, glosas y comentarios, guía, autobiografía, sistema (geométrico o no), aforismo, ensayo, pensamientos o soliloquios, diario, novela, etc. Todas tienen su razón de ser formal, propia de un contexto y de unos temas, o de un talante personal... y ninguna debe ser excluida del concierto filosófico por prejuicio. Pues bien, el texto fragmentario es parcialmente común a varias de las expresiones señaladas, y en este sentido tiene cierto carácter transversal, si bien a nada se contrapone tanto como a la pretensión de sistema y con nada coincide tanto como con el aforismo. En éste vamos a centrarnos, toda vez que es necesario delimitar un tema para profundizar en él e incluso acotar una extensión media del discurso fragmentario, que fijamos desde una línea a unas pocas páginas. Lo entendemos, pues, de modo amplio, lo que quiere decir que no tiene unas características fijas y estrechas; por cjemplo, no siempre tiene que ser muy breve y concentrado, ni acuparse de asuntos normales... Así, no se trata sólo de apotegmas ejemplarizantes al modo de Plutarco o Erasmo, ni de sentencias o proverbios exclusivamente, como tampoco se reduce a reglas de vida y ni siquiera a las agudas observaciones de todo tipo propias de algunos ilustrados franceses, por citar otro caso.

Sin duda, el fragmento como aforismo que aquí elegimos puede participar de ello, pero tiene un específico contenido filosófico que intentaremos exponer, versátil, a veces disperso pero sin renunciar a la coherencia, teórico y práctico a la vez: capaz de ofrecer explicaciones parciales de lo real, resolver algunos problemas y crear sentidos. Por lo que se refiere a la forma, es claro el afán de 
concisión y densidad, pero haciendo valer la potencia diferencial de todo lenguaje, que es multívoco, abierto y generador inagotable, en vez de simple trasunto categorial de la descripción ontológica. Aquí el discurso filosófico ocupa una posición intermedia entre el científico y el literario de manera paradigmática ${ }^{1}$. Queremos decir que, sin mezclar ni confundir los ámbitos, hay que abrirse desde el conocimiento enunciativo-profesional hacia otras formas de conocimiento menos logicas, más flexibles al anteponer la «mostración» a la «demostración», y cuyo lenguaje a menudo recurre a la metáfora y a la connotación, además de la denotación. El texto fragmentario nos parece el lugar privilegiado para todo ello, precisamente porque ni la forma ni el fondo son metódicos y sistemáticos, sino abiertos a la diversidad irreductible y a la convergencia de perspectivas: la propia noción de concepto es modificada porque se ensancha a la par que pugna contra la abstracción. Tal es el punto de partida de la crítica que supone hacia otras expresiones discursivas y por eso encarna una opción filosófica concreta.

A modo de presentación temática, puede hablarse de una posición global desde la que aquí se piensa, de una concepción básica de la realidad que el fragmento encierra y de una intención última a la que se orienta. Posición perspectivista casi por principio, ceñida a las experiencias intuitivas de toda índole antes que a la especulación, empezando por cuestiones inmediatas (p. ej., psicofisiológicas), y donde ciertas actitudes y vivencias personales modulan el resto, lo que se plasma en un peculiar «estilo» de pensamiento. Negación, pues, de lo impersonal que implica la preeminencia de lo biográfico (en sentido amplio) respecto a lo bibliográfico; o, en otro plano, la importancia del sentido y el valor junto al aspecto propiamente veritativo. Haya una posición afirmativa o negativa de conjunto, tampoco es infrecuente algún tono escéptico, irónico y/o emocional en general, en el marco de esa relativa subjetividad. En cuanto a la concepción, quizá lo más destacado sea el énfasis en lo individual (no hay géneros ni especies) como fundamento ontológico, es decir, hay un cierto cariz «nominalista» coherente con la pluralidad de perspectivas y perfectamente acorde con la expresión fragmentaria. Por eso encontramos constelaciones o archipiélagos de objetos y conceptos, pero nunca totalizaciones cerradas, y por eso también el texto se alimenta de casos y cosas particulares, historias, personajes, escenas, anécdotas, datos que provienen de la prensa o de viajes, entre otras muchas fuentes... En conjunto, puede decirse que no importa tanto describir lo real en términos universales (órdenes diversos, leyes, axiomas, fines, etc.) cuanto destacar aspectos específicos y parciales, aun pasajeros y dinámicos, más propios de la esfera genuinamente humana que de la natural, por así decir; lo que cabe denominar «artificialismo» frente a «naturalismo». Desde luego son dimensiones complementarias, pero acaso se vea el matiz introducido al decir que la intención es ante todo práctica, comenzando por una suerte de «terapia» para cada autor y en seguida prolongada hacia la ética y la política. Resulta habitual encontrar en esta clase de textos una versión crítica de lo convencional y establecido en forma de ideas y creencias, uso y cos-

${ }^{\prime}$ Cf. G. Gabriel, Zwischen Logik und Literatur. Erkenntnisformen won Dichtung, Philosophie und Wissenschafi, Stuttgart, 1991. Este es un tema más amplio, pero cabe aplicarlo al texto fragmentario en particular. 
tumbres primordiales, de todo lo dado como primer producto socio-cultural para la vida. Por otra parte, el aforismo no pide asentimiento ante lo ya acabado, sino que invita a proseguir la indagación por cuenta propia, e incluso a elaborar cierta dialéctica entre teoria y praxis (individual y colectiva, en la mente y en la acción), que no tenga fin.

Este boceto general va a ser explicado en el apretado estudio de tres autores muy diferentes que ofrecen así perspectivas históricas y temáticas diversas: Lichtenberg, Nietzsche y Adorno ejemplifican tres siglos de pensamiento alemán en unas ciertas líneas, es decir, pertenecen a una misma cultura, aunque todos critican el nacionalismo patrio y abogan por la apertura cosmopolita. Además, los posteriores leyeron con interés a los anteriores, de tal manera que Nietzsche elogia y frecuenta a Lichtenberg, mientras que Adorno se refiere bastantes veces al autor del siglo xIX. En definitiva, a través de tres estilos y enfoques distintos quizá sea posible ver algunas características comunes del texto fragmentario - sin pretensión de exhaustividad, desde luego-, amén de posibles semejanzas de fondo entre los autores, una vez salvadas las distancias obvias. Por último, diremos que en este comentario también se va a hacer uso del fragmento en forma de epígrafes que recojan con brevedad y concisión los aspectos más relevantes de cada caso, en aras de la agilidad que exigen los límites de la exposición.

\section{En relación a Lichtenberg}

G. H. Lichtenberg (1742-1799) es un ejemplo paradójico de reconocido científico natural en su tiempo que pasa a la posteridad por esa gran colección de miles de anotaciones de todo tipo que se sitúa entre el pensamiento, la literatura informal y el mero apunte, según dictara la circunstancia. Escritor impenitente de fragmentos múltiples cuyo único fin era ayudarle a pensar, esto es, a vivir; investigador pragmático y antimetafísico de todo lo humano; anglófilo, constitucionalista e ilustrado cabal. Hombre de mala salud y buena curiosidad, depresivo y jorobado, supo hacer de la pirueta asistemática y a menudo humorística musculosas reflexiones y lúcidos epigramas. Para entrar en materia, digamos que él concibe esa miscelánea como esbozos que aguardan, no la reescritura perfeccionista, sino los rayos del sol para germinar; o como las búsqueda de aquel pensamiento que haga morir de risa a cuantos lo oigan; o aquella capacidad de síntesis y plenitud que querría formular un libro en una palabra ${ }^{2}$. Es decir, unos textos incisivos, reposados o chispeantes, aunque sin pretensiones de zanjar ninguna cuestión, y menudos en el planteamiento, pero ambiciosos en el alcance. Más exactamente, se trata de borradores que - por analogía con los libros de comercio- anotan el día a día del espíritu sin mayor orden, por vía directa e indirecta, para luego ser pulidos, estructurados y comentados en forma de una personal acontabilidad" de la vida (E-46). De hecho, tal sis-

${ }^{2}$ Cf. Sudelbuicher, B-205, D-137 y E-224, respect., W. Promies (ed.), C. Hanscr Vcrlag, Munich, 1968-1971. La letra responde al cuademo de anotaciones (scgún años) y el número al texto. Aquí seguimos la traducción de Juan del Solar en su excelente edición de Aforismos (antologia), Madrid, Edhasa, 1991, 3. ${ }^{\text {ed }}$. 
tematización no se hace nunca y lo que importa ahí es la metáfora de la transacción y el intercambio constantes, donde todo tiene cabida c interés: «El método del cuaderno borrador es altamente recomendable. No dejar de anotar ningún giro, ninguna expresión. A la riqueza también se accede ahorrando verdades de pacotilla» (F-1219). De nuevo una metáfora económica, acaso con el tono burgués de la acumulación frente al derroche vital, o contra la dispersión a veces dolorosa del tiempo y de la identidad, pero siempre al servicio de lo espontáneo - casi azarosoy de esas pequeñas cosas esenciales que conforman la existencia. Es la cotidiana reflexión sobre detalle y matices la que fragua eso que llamamos sabiduria, y que se expresa con libertad formal incluso en la ciencia: «No el método matemático sino el paradigmático, no el sistemático sino el escepticismo, no el resultado sino el experimento y la hipótesis impregnan su pensamiento científico-natural (...), no la forma científica cerrada y sistemática del tratado, sino la forma abierta y literaria del aforismo»; porque las cosas del mundo se descubren «en la interdependencia de fantasía y observación, instinto y razón, lo general y lo particular, tanto argumentativa como intuitivamente ${ }^{3}$. Lo vamos a comprobar de la mano de algunos contenidos centrales, intcrrelaciones entre sí en mayor o menor medida, a la vez que con su expresión fragmentaria.

1. Punto de partida. A pesar de la diversidad, puede formularse un presupuesto ontológico y otro epistemológico correlativos, que se proyectarán sobre el resto de temas cual semillas a desarrollar: se trata de la improbabilidad de encontrar un primer elemento de la materia y los consecuentes principios universales para las ciencias, toda vez que «La naturaleza no crea genera ni species, sino individua, y nuestra miopía ha de buscar similitudes para poder retener muchas cosas a la vez. Estos conceptos se vuelven tanto más inexactos cuanto mayores son los géneros que inventamos» (A-17). Hay cierto nominalismo empírico que recela de abstracciones conceptuales y lingüísticas (C-278), por lo que tienen de homogeneización de lo diferente, amén de constatar que sólo son invenciones útiles, como se verá. De donde afirma el autor alemán que no hay «una medida universal» para las cosas y que en sentido valorativo «La medida de lo maravilloso somos nosotros», so pena de que todo se iguale (A-110). Tal es una premisa del artificismo enunciado más arriba, sin que ello suponga un tosco antropomorfismo: los puntos de vista humanos se contrastan y aquilatan entre sí, en el seno de una red de relaciones primero sensoriales y luego sociales. Como enseña el «idealismo» kantiano, y más allá de las resistencias que despierta, «ya que todas las cosas se hallan interrelacionadas en la naturaleza, ¿qué puede haber más real y verdadero que estas relaciones? ", que en ocasioncs me implican y conciernen ( $\mathrm{H}-19)$. Ahora bien, debe quedar claro que nuestras representaciones y sensaciones nada dicen sobre la realidad objetiva exterior, que nos resulta inalcanzable y de la que ni siquiera podemos asegurar que actúe casualmente sobre nosotros (H-150); es decir, «conocer objetos exteriores es una contradicción», ya que sólo podemos conocemos a nosotros mismos,

${ }^{3} \mathrm{C}$. Schildknecht, «Entre las ciencias y la literatura: formas literarias de la filosofias, pp. 21-40, en M. T. López de la Vieja (ed.), Figuras del logos. Entre la filosofía y la literatura, Madrid, FCF, 1994, respect, pp. 37 y 39 . De la misma autora puede consultarse Philosophische Masken, Literarische Formen der Philosophic bei Platon, Dexartes, Wolf und Lichtenberg, Stuttgart, 1990, pp. 123-169. 
y además todo el saber humano se formula en un lenguaje preexistente, lo que implica que «cuando habla, la filosofía se ve siempre obligada a usar el lenguaje de la no-filosofía» (H-151). En efecto, el lenguaje es en sí una filosofía universal (cosmovisión popular), mientras que la filosofía técnica es un subconjunto que rectifica y restringe aquélla (H-146). Y este paralelismo con Humboldt sirve para abundar en el fenomenismo, ahora similar al de Hume, recién expuesto: no hay causas ni certezas, sólo sensaciones y asociaciones relacionales que adquieren sentido en un contexto lingüístico previo. De aquí, a su vez, se derivan dos tesis capitales: Lichtenberg afirma que hay que distinguir entre significar y ser, pues causa muchos problemas el creer que «las cosas son realmente lo que sólo significan» (A-114) una vez que no podemos sobrepasar la creencia y tocar lo real (C-375); en segundo lugar, la filosofía es fruto de la intersubjetividad, «según las normas de una evaluación racional de los grados de probabilidad. Aquellos principios sobre los que todos los hombres están de acuerdo, son verdaderos. Si no lo fueran, no tendríamos verdad alguna» (A-136). Así, el marco hermenéutico remile a una dinámica de consensos en torno a ciertas verdades, que se prolonga en variables términos culturales e históricos (C-223). Como se ve, para concluir, cualquier discurso sistemático resulta difícil a partir de estas posiciones de partida (que hemos concentrado al máximo), y son mucho más adecuadas incursiones fragmentarias sobre parcelas singulares de lo real.

2. Actitudes e intereses básicos. Con los presupuestos anteriores es claro el rechazo de todo dogmatismo y la posición de un escepticismo moderado y tolerante. En efecto, también la duda debe ser limitada a su condición de «atenta vigilancia» (F-447), aunque en principio lo adecuado sea «ni negar, ni creer» (L-18). Hay que propiciar cierto talante abierto y constructivo, dialogante con el mundo pero no iluso, avisado pero no resentido ni suspicaz. En conjunto, puede decirse aquello de primum vivere, deinde philosophari, pues Lichtenberg prescribe como adietética para la salud del entendimiento» (D-251) atender ante todo a la vida real y concreta, el trato con la gente y las ocupaciones diversas como la mejor escuela: «El fundamento de todo es la observación y el conocimiento del mundo» (E-265), ya que leer mucho vuelve orgulloso y pedante, mientras que ver mucho nos hace «sabios, sociables y útiles», esto es, «ciudadanos del mundo» (H-30). También el aprendizaje es fragmentario y perspectivista a lo largo de la existencia (y como tal se plasma), dado que la experiencia es limitada y unos hechos se contrastan con otros. Pero su carácter es eminentemente práctico, según se deriva de la posición teórica: «El mundo no está ahí para ser conocido por nosotros, sino para que nos formemos en el. Esta es una idea kantiana» (J-898), lo que significa que el saber no se muestra, sino que se utiliza (KA-262). La coherencia es grande en sentido intra y metadiscursivo porque el autor hace lo que aconseja: mirar, pensar y anotar, de acuerdo al fluir de la vida con sus facetas innumerables que no aspira a totalizar, para desenvolverse lo mejor posible en cada situación.

Si damos un paso más encontramos una atención por lo inmediato que será muy del gusto de Nietzsche. Así, primero en términos psicofisiológicos, hay que reparar en que los alimentos ejercen «una enorme influencia en el estado anímico de los hombres» (A-43), por dar un ejemplo significativo. Si las grandes teorías 
quedan desplazadas, fijémonos en lo más próximo, parece decir Lichtenberg una y otra vez. Y lo que cs más, scamos conscientes de que el conocimiento responde a ello: «En todas las clases sociales la Ilustración consiste realmente en tener conceptos precisos de nuestras necesidades esenciales» (J-246). Lucgo la cpistcmología se tiñe de política en un segundo momento, lo que explicita el pragmatismo anunciado. Retomemos los dos planos - psicofísico y social - desde otro ángulo: hay un imperativo de salud como interés primordial, que se viste de alegría ( «la salud prefiere ver al cuerpo bailando que escribiendo», sin fecha, p. 19) y ensalza la «jovialidad» y la aligereza» como los mejores atributos espirituales, según enseña la experiencia biográfica al autor (B-81). Por otro lado, con estas premisas es comprensible que el ser humano opte siempre por algo en función de su estado y necesidad: «el ser humano es siempre parcial y hace muy bien en serlo», puesto que la imparcialidad es artificiosa y por eso mismo parcial (F-578), esto es, creada y no natural. La neutralidad pura no existe e incluso perjudicaría la vida - entendemos-, ya que tampoco hay normas universales en clave iusnaturalista. Por el contrario, es la energía más íntima de cada uno quien tiene la iniciativa, y si es posible en forma expansiva y dichosa: el estilo del pensamiento que mencionamos al inicio va configurándose de manera inequívoca como arte que correlaciona ráfagas de vida y de texto... Para terminar, digamos que Lichtenberg no deriva una concepción de la naturaleza humana ingenua ni unilatcral: cuerpo y espíritu son uno "satélite" del otro en pie de igualdad (D-16), a medio camino jocoso entre el "primo ángel» y el «primo mono» (D-436); pero lo que caracteriza al ser humano sobremanera es la capacidad de hacerse a sí mismo, la plasticidad autocreadora que le distancia del animal (F-433). Ahí es todo posible y por eso los campos de su actividad son ilimitados y dispares: «Lo que siempre me ha gustado en el hombre es que, siendo capaz de construir Louvres, pirámides eternas y basílicas de San Pedro, pueda contemplar fascinado la celdilla de un panal de abejas o la concha de un caracol» (D-398). Semejante pluralidad y libertad creadora, tal variedad de planos e intereses parecen invitar una vez más a ser recogidas en una multitud de textos fragmentarios, singularizados, que les hagan justicia de modo inmanente, por así decir, sin imperativos generales ni exclusiones.

3. Diseño de la filosofía. Como resultado de todo lo anterior, la concepción que Lichtenberg tiene de la filosofia no puede ser macrologica, sino necesariamente microfisica. En primer lugar, no hay un Yo sustancial pensante, sino un conjunto de «sensaciones, representaciones y pensamientos. Deberia decirse impersonalmente piensa, como se dice relampaguea. Decir cogito es ya decir demasiado en cuanto se lo traduce por yo pienso. Suponer el Yo, postularlo, es una necesidad práctica» (K-76). De nuevo la línea que de Hume conduce al Kant dual de la primera y segunda críticas: disolución de la identidad cognoscente que se impersonaliza, y reconstrucción posterior en razón de imperativos morales. A este esquema formal le corresponde otro material simétrico: cada sujeto tiene/es un conjunto particular de pensamientos llamado «sistema de ideas» (sistema de opiniones, convicciones y sensaciones), de carácter abicrto e interactivo, que recoge su cosmovisión individual (B-262). De hecho, lo que cada cual debe hacer es construirse una propia y personal, en consonancia con una vida independiente (B-264); en otras palabras, 
cultivar las propias opiniones, sentimientos y observaciones, sin dejarse llevar por lo ajeno, la tradición y los tópicos vigentes (D-121, F-734). Naturalmente, vuelve a surgir la idea de perspectivas o fragmentos ahora ensamblados, articulados por la reflexión y la experiencia vital. El resultado es una filosofía que toma como modelo a los antiguos en tanto que; $a$ ) no imitaban permanentemente; $b$ ) no tenían espíritu sistemático; c) aprendían más cosas que palabras; d) no escribían tanto para ganarse el pan, y e) observaban más la naturaleza (D-264). Aquí se resume la concepción de Lichtenberg que venimos desgranando y su contraposición al academicismo libresco ( "Traficaba con opiniones ajenas. Era profesor de filosofia», K-246), y a un supuesto purismo aséptico ( «Sin que se note, la filosofía pura sigue manteniendo $-y$ no puede evitarlo-- relaciones amorosas con la... impura. $Y$ así será hasta el fin de los tiempos», L-35). La realidad envuelve a los discursos, los une y separa en función de sujetos y contextos, por lo que deben integrarse todos los factores posibles: la filosofia, en fin, como mosaico de experiencias y conocimientos.

De ahí que el autor alemán apele tanto a la razón fría como al cálido sentimiento ( $\mathrm{L}-406)$; al «Sentido común» vigilante que intuye «la verdad de unos cuantos principios de utilidad general» (F-56); al juicio, pero también a la agudeza y el ingenio, «ente reductora» que ve lo universal en lo particular (F-700). Lejos, pues, de las alucubraciones metafisicas» que realizan «quienes no pueden hacer nada mejor» (E-411), lo correcto es aplicar un principio de economía que rechace cualquier «Deus ex machinas (E-460), por ejemplo, respecto a la inmortalidad del alma y la vida ultraterrena ( $F-489$ ), $y$, en general, reconozca que «la ignorancia aumenta al mismo tiempo que sus conocimientos» (F-462). La filosofía, extrapolamos, será así una actividad más humilde y fecunda, más útil y práctica en todos los órdenes, cercana a los asuntos concretos de la vida. Su labor primera consiste entonces en cuestionar los convencionalismos $\mathrm{c}$ investigar todo aquello que se da por supuesto acriticamente (KA-291); es decir, librarse de «la costumbre (que) echa a perder la filosofía» y «poder ver, oír y sentir todo de nuevo» (H-21). Para no quedarse en simples palabras, he aqui dos piedras de toque de gran envergadura en esa crítica: el principio de razón suficiente es ley necesaria del pensamiento, principio lógico indiscutible, pero «otra cuestión es, sin embargo, la de saber si es un principio objetivo, real o metafísico» (J-757); por otro lado, la doctrina de la libertad humana no es otra cosa que una cómoda, habitual y preferible «hipótesis falsa» que sólo tiene las apariencias a su favor (J-278). Con lo que volvemos al comienzo de este epígrafe, pero con unas conclusiones más demoledoras aún: Lichtenberg pone en entredicho los pilares (teórico y práctico) del pensar tradicional sin renunciar a su conveniencia operativa - casi ficcionalista-, ni cacr en el nihilismo. No extraña que profetice con acierto la vocación autofágica de la filosofía («acabará por devorarse a sí misma», J-620), como conclusión radical de su misión (auto)crítica, máxime si es aplicada a modelos caducos. Por todo ello, también aquí se impone el fragmento personal como única vía, en la medida en que cumple el mandato esencial: «Permanece atento, no sientas nada en vano, mide y compara: tal es toda la ley de la filosofía” $(\Lambda-130)$.

4. Consecuencias e ilustraciones. En este último apartado pretendemos mostrar ejemplos derivados de lo anterior, cual mónadas que reflejan la realidad. Nuestro 
autor invita siempre a la sabiduría de lo pequeño y cotidiano (KA-296), sirviéndose a menudo del lenguaje metafórico, «especie de lenguaje natural» arbitrario pero preciso (D-468), lo que nos dice mucho de su apertura a la empatía literaria. En sentido objetivo, las cosas más grandes se cumplen gracias a causas pequeñas acumuladas que solemos pasar por alto (A-19); idea que lleva a nuestro autor a una intuición muy próxima a recientes teorías cuando dice que escribir un libro puede influir en la conversación ciudadana a $\mathrm{X}$ hora mil años después, o que tirar al mar una pepita de cereza en Alemania cambia la posición de una gota de agua en el Cabo de Buena Esperanza (D-55) Y en sentido subjetivo, «la tendencia humana a juzgar importantes las pequeñas cosas ha producido muchas grandes cosas» (G-234), lo que, por reciprocidad, hace más comprensibles opiniones como éstas: descubrir un remedio infalible contra el dolor de muelas es tan valioso como descubrir un nuevo planeta (G-241); de nada sirve ser muy espiritual y/o cerebral si uno no sabe pegarse un botón (D-452); y si un corazón puro es cosa excelente, una camisa limpia también (F-885)... Breves apuntes sazonados con humor que expresan toda una concepción de la vida y que también saben llamar a la seriedad cuando hace falta o dar un giro temático profundo sin salirse de los intereses básicos. Así, por ejemplo - y esto es otra miscelánea-, la gran importancia que Lichtenberg concede a los sueños (parte sustancial de la existencia, cuya consciencia define al hombre, F-743), o a la necesidad de limpiar de sutiles supersticiones la propia vida y las religiones positivas que de ello se aprovechan $(\mathrm{H}-42) ; \mathrm{y}$, más ampliamente, el no confundir la fe - que el autor alemán parece tener- con oscuras ideas de causalidad que llevan a un Dios del cual nada podemos saber, «Pues explicarlo todo a partir de un creador del mundo es siempre antropomorfismo» (J-944). En definitiva, cierto deísmo de corte spinozista (H-143), tan común en la êpoca entre cierta elite, como es sabido, que insiste en la exigencia de madure $z$ mental y espiritual: tan alejada de los cuentos felices (a veces el mundo parece una broma de mal gusto y el optimismo leibniziano es injustificable, K-69), como de los cuentos de miedo.

Por otra parte, la perspectiva monadológica se aplica por completo en la moral y la política: «En los pequeños sucesos cotidianos de pacotilla reside lo universal moral exactamente como en los grandes, según saben unos pocos adeptos» (B-195). Todo está ejemplificado en esta fórmula respecto al fondo y la forma del texto fragmentario, y Nietzsche y Adorno sabrán sacarle partido, completando incluso la incipiente dialéctica de la llustración que aquí aparece: «Es muy triste ver que el esfuerzo de los hombres por disminuir los males del mundo produzca tantos males nuevos» (L-236); «Se habla mucho de Ilustración y se desean más luces. pero, ¿de qué sirve tanta luz, Dios mío, si la gente no tiene ojos $o$, si los tiene, los cierra intencionadamente?» (L-472). Y en particular, Adorno desarrollará las críticas contra los abusos económicos y políticos de los poderosos (E-131), contra el «despotismo religioso y de sistema» (F-431), aunque en el siglo $x x$ sabrá ya que no basta con el formalismo de la «igualdad a través de las leyes» (K-296). Sin embargo, la lucidez histórica de Lichtenberg, aun circunscrita a su tiempo, no le impide sentenciar "Nosotros: jornaleros, vasallos, negros, siervos de la gleba, etcétera, por la desgracia de Dios...» (K-240), cual amarga proclama universal y 
perenne. En cualquier caso, vamos a terminar nuestro condensado recorrido por su obra con un texto fiel a su espíritu y al de nuestro tema, que habla por sí mismo: «Hacer que cada momento de nuestra vida sea el mejor posible, independientemente de qué mano del destino provenga y de si es favorable o desfavorable: en esto consiste el arte de vivir y el verdadero privilegio de un ser racional» (G-212).

\section{En relación a Nietzsche}

La figura de Nietzsche no necesita presentación en este terreno, dado que es uno de los mejores pensadores en texto fragmentario y un artista del aforismo. Lo fundamental otra vez es que la crítica de la cultura y de la filosofía que lleva a cabo implica el rechazo unitario y simultáneo de la forma y el fondo de esos discursos: atacar el tratado o el sistema filosófico significa atacar casi toda la posición-concepción-intención triunfante en la historia del pensamiento occidental, y viceversa; vituperar la «dialéctica» conlleva poner en solfa el encadenamiento de razones y la arquitectura conceptual. El propio autor nos lo sintetiza en una frase: «discurso corto, sentido largo - ihielo resbaladizo para la burra!» ${ }^{4}$. Esto es, decír mucho con pocas palabras e invitar a una compleja interpretación de lo apuntado, cosa imposible para tantos ineptos. No se trata de extenderse en pruebas de supuestas verdades, sino en inventar, comprender y asimilar valores y sentidos que sirvan al fortalecimiento de la vida. Nietzsche nos introduce el tema así: «El aforismo, la sentencia, en los que soy el primer maestro entre alemanes, son las formas de la "eternidad"; es mi ambición decir en diez frases lo que todos los demás dicen en un libro - lo que todos los demás no dicen en un libro...!» $(\mathrm{Cl}$, Incursiones de un intempestivo, p. 51). Tal es el derroche de lucidez y concision que se propone como prenda de eternidad o, lo que es lo mismo, como fogonazo en el instante atemporal, sin dejar por ello de ser «intempestivo», pues también aquí alienta la intención polémica contra los que ni siquiera en todo un libro llegan tan lejos. $\mathrm{Y}$ es que -como se ha dicho- Nietzsche piensa en «relámpagos», es intuitivo y gráfico en grado sumo, escribe como si tallara piedras, y cada conjunto de aforismos tiene su propio tempo y relación para conformar un libro unitario y diferente del resto; pero quizá esto mismo oculta su pensamiento (por falta de sistema) e incluso le lleva al efectismo estético y sofístico, «mezcla inquietante de... pensamiento originario y de abismal desconfianza del pensar frente a sí mismo» ${ }^{5}$.

Examinémoslo un poco más y veremos que nuestro filósofo ofrece respuesta para eso: en efecto, es consciente de la dificultad que presenta la forma aforística por ser inactual, pero en absoluto renuncia a la reflexión. «Un aforismo, si está bien acuñado y fundido, no queda ya "descifrado" por el hecho de leerlo; antes

${ }^{4}$ Más allá del bien y del mal -en adelante, BM-, VII, 237. El significado del resto de abreviaturas es el que sigue: GM, La genealogía de la moral; CI, Crepúsculo de los idolos; AC, El Anticristo; EC, Ecce homo; GS, El gay saber. Seguimos las excelentes traducciones de A. Sánchez Pascual, Madrid, Alianza Editorial, y citaremos por secciones o partes y número de texto.

'Cf. E. Fink, La filosofia de Nietzsche, Madrid, Alianza Universidad, 1982, 5." ed., pp. 14 ss. 
bien, entonces es cuando debe comenzar su interpretación, y para realizarla se necesita un arte de la misma» (GM, Prólogo, p. 8). Prueba de este «modo de lectura como arte» es la importantísima tercera parte de la misma obra sobre los ideales ascéticos (que es un extenso comentario de un aforismo que dice: «Despreocupados, irónicos, violentos, así nos quiere la sabiduría: es una mujer, ama siempre únicamente a un guerrero» de Así habló Zaratustra); tarea para la cual hace falta parecerse a la vaca y numiar sin descanso (ibid.) Por consiguiente, después del primer impacto hay que seguir trabajando el texto, insistiendo en la búsqueda de sentidos, de indicios y claves para descifrarlo. Lo que ocurre es que no sirve el tipo de pensamiento tradicional, sino que hace falta otro bien distinto, creador y perseverante a la vez, acaso también despreocupado, irónico y violento. Por otro lado, los problemas profundos exigen una incursión rápida (como un baño en agua fría), una iluminación al vuelo ( $\sin$ dar tiempo a la esclerosis); coger lo escabroso "por sorpresa» y decirlo en poco tiempo para ganar la atención; en definitiva, «un rápido ir y venir» libre y aventurero (GS, V, p. 381). Descalificar este proceder antimetódico supone - según Nietzsche - caer en los prejuicios de los sistemáticos y desconocer la verdadera experiencia sapiencial, que es la que nos da una explicación de fondo: es la inspiración, es decir, la revelación y el éxtasis donde no es uno el que delibera, sino que «de repente, con indecible seguridad y finura, se deja ver, se deja oír algo, algo que le conmueve y trastorna a uno en lo más hondo»; abismo de felicidad y dolor, instinto para las formas... «Todo acontece de manera sumamente involuntaria, pero como en una tormenta de sentimiento de libertad, de incondicionalidad, de poder, de divinidad... La involuntariedad de la imagen, del símbolo, es lo más digno de atención; no se tiene ya concepto alguno; lo que es imagen, lo que es símbolo, todo se ofrece como la expresión más cercana, más exacta, más sencilla» (EH, Así habló Zaratustra, 3). Sin duda, esto ocurre en momentos excepcionales, pero es nuclear, y con toda consciencia el símbolo y la imagen se antepone al concepto para expresar algo que no es discursivo ni csquemático. Antes y después resulta necesario el arduo trabajo de comentario que lo comprende y desarrolla. No es algo irracional, sino arracional, complementario del estudio genealógico, semiótico, etc., $y$, sobre todo, plural: todo (cada acontecimiento, fenómeno, palabra, pensamiento) tiene sentidos múltiples y expresa fuerzas diversas a evaluar, lo que produce el pluralismo consustancial a la filosofía y la única garantia de libertad ${ }^{6}$. Por eso es inevitable un pensamiento en fragmentos, abierto y versátil, múltiple y poliscópico, complejo y no lineal, ajeno al monotésmo de la razón. Aquí hay una toma de partido clara por un estilo y una manera de filosofar. Veámoslo.

1. Contra el sistema. Es conocida la crítica de Nietzsche a la teoría del conocimiento imperante en la filosofía occidental, de entrada por no ser consciente de su verdadera naturaleza ficticia: los juicios falsean lo real por principio, lo simplifican para facilitar su manejo, i. c. la supervivencia, e inventan mundos idénticos e incondicionados para un mejor crecimiento vital; por eso los juicios falsos (incluidos los sintéticos a priori) son imprescindibles, y admitir la no-verdad es condición de la vida, lo que ya nos coloca más allá del bien y del mal (BM, I,

\footnotetext{
${ }^{\circ}$ Cf. G. Deleuze, Nietzsche y la filosofia, Barcelona, Anagrama, 1986, 2., ed., pp. 10 ss.
} 
p. 4). El concepto, en su doble vertiente teórica y moral, homogeneiza lo singular en torno a las nociones de identidad y libertad, con lo que se elevan sanciones y metáforas pragmáticas al rango de verdades universales. Se habla entonces de sujetos, objetos, causas, leyes, necesidad, motivos, fines, números, etc., aunque se olvida su origen mitológico (BM, I, p. 21). Y este abandono del fundamento biológico y plural de los instintos ha desembocado en la monolítica «ecuación socrática de

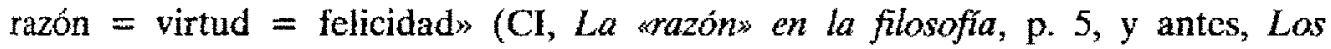
cuatro grandes errores, p. 3), se nos dice como compendio simbólico. He aquí, pues, críticas semejantes a las aparecidas en Lichtenberg: contra el triunfo de lo abstracto y de sus correspondientes imperativos teóricos, morales y religiosos, y contra la alianza semántica de verdad, bien y belleza, con el oportuno soporte teleológico, hasta acuñar la culpabilizadora noción del «orden moral del mundo» que infecta la inocencia del devenir por medio del «castigo» y la «culpa»: «El cristianismo es una metafísica del verdugo" (CI, Las cuatro grandes errores, p. 7).

Todo ello forma un entramado común, donde unas facetas sostienen a otras, de tal manera que resulta un gigantesco sistema hecho de engaño y opresión. $\mathrm{Ni}$ siquiera los ateos, escépticos o inmoralistas al uso han escapado al último ideal de la verdad en beneficio de la pura interpretación, que consiste en «violentar, reajustar, recortar, omitir, rellenar, imaginar, falsear" (GM, III, p. 24) al servicio de la pujanza vital. Ésta es la gran revolución que Nietzsche propone y la que le hace resumir en un aforismo su rechazo: "Yo desconfío de todos los sistemáticos y me aparto de su camino. La voluntad de sistema es una falta de honestidad» (Cl, Sentencias y flechas, p. 26). El sistema siempre es reduccionista sin reconocerlo, atropella la pluralidad del llamado «mundo de la apariencia», niega el perspectivismo que le es consustancial para vivir. Por el contrario, hay que negar la falsa objetividad del «mundo inteligible», el desinterés hipócrita del saber, «de modo que sepamos utilizar en provecho del conocimiento cabalmente la diversidad de las perspectivas y de las interpretaciones nacidas de los afectos». Nada es puro, absoluto y en sí, neutro o unilateral, sino que «cuanto mayor sea el número de ojos, de ojos distintos que sepamos emplear para ver una misma cosa, tanto más complejo será nuestro "concepto" de ella, tanto más completa será nuestra "objetividad" (GM, III, p. 12). Y la forma escrita de expresar esta riqueza es el texto fragmentario, atento a cada optica y matiz, presto a los cambios del devenir, portavoz de los diferentes instintos. Pues, bacaso no es el ser humano mismo kun fragmento de fatum» (CI, La moral como contranaturaleza, p. 6), que como tal se autoexpresa?

2. Consecuencias e ilustraciones. Corresponde ahora derivar efectos de ese planteamiento y dar ejemplos concretos de la alternativa propuesta, es decir, ilustrar en el doble sentido. En el sistema hay definiciones y conceptos, pero sólo en la medida en que se trata de algo sin historia, cuando lo que tiene historia -que es todo objeto de interpretación- no puede ser definido (GM, Il, p. 13). Por eso Nietzsche propone «definiciones» peculiares, plasmadas en aforismos, que muy poco tienen que ver con la secuencia lógica de corte deductivo o analítico y menos con el orden pesado de las conexiones formales, pues se trata de que los conceptos y las palabras bailen igual que los pies (CI, Lo que los alemanes están perdiendo, 
p. 7). Lo que significa que tengan una ligereza no lastrada por la pretensión de universalidad y permanencia, que sepan hacer de la metáfora y del símbolo su ariete. Así, Zaratustra es un «danzarín» cuyo pensamiento nuclear es un ilimitado decir sí a todas las cosas en el eterno retorno, «Pero esto es, una vez más, el concepto de Dionisio», y su lenguaje será el «ditirambo» (EH, Así habió,., pp. 6 y 7 , respect.). Lo que importa entonces es la actitud afirmativa antes que la mera repetición de lo mismo como tesis cosmológica, la alegría que canta a todo lo existente y que se deja encarnar por el arquetipo de Dionisio, concepto contrapuesto precisamente a Apolo, el dios de la forma y del conceptualismo hecho mármol, si vale la expresión. Otra lectura posible de aquella actitud es la aceptación de todo lo antitético como índice de riqueza y fecundidad (CI, La moral como antinaturaleza, p. 3), esto es, la diferencia irreductible que escapa al concepto habitual y sólo condesciende al símbolo polimorfo.

Desde otro ángulo, también aquí es fácil encontrar textos aforísticos que reflejan cual mónadas deslumbrantes el conjunto del pensamiento práctico nietzscheano, y con una capacidad de síntesis extraordinaria. Son ejemplos vivos que hablan de la fuerza del fragmento: «No existen fenómenos morales, sino sólo una interpretación moral de los fenómenos» (BM, p. 108); y he aquí otro ejemplo que desarrolla lo anterior: «¿̇Oué es bueno? Todo lo que eleva el sentimiento de poder, la voluntad de poder, el poder mismo en el hombre. / ¿Qué es felicidad? El sentimiento de que el poder crece, de que una resistencia queda superada...* (AC, p. 2). Si nos preguntamos por el tipo humano global que se propone, la respucsta es fácil: «la objeción, la travesura, la desconfianza jovial, el gusto por la burla son indicios de salud: todo lo incondicionado pertenece a la patología» (BM, p. 154). Tal es un espiritu lúcido y lúdico, valiente y al servicio de los instintos artísticos, creadores; alguien para quien «dicho en una fórmula: su virtud es consecuencia de su felicidad» (CI, Los cuatro grandes errores, p. 2). Ciertamente, en esta frase cabe todo un mundo ético, el de la autonomía frente a la heteronomía, el de la inmanencia frente a la trascendencia, la afirmación contra la negación. En última instancia, el modelo humano de grandeza es aquel que hace suyo el amor fati sin reservas, a la par que trata todo lo esencial como un juego, contrario al gesto sombrío y afectado (EH, Por qué soy tan inteligente, p. 10), y donde cada nota atempera a la otra para juntas apuntalar la noción de una filosofía trágica, aquí apenas esbozada.

3. Para una crítica de la civilización. 'La pluralidad consustancial a la filosofía de Nictzsche ofrece bastantes perspectivas para realizar una crítica fragmentaria del modo de vida occidental, también en sentido sociopolitico y económico. Con este pequeño apunte tendemos un puente hacia Adorno, buscando algunas conexiones por indirectas que sean. Así ya en el siglo xIX puede describirse la modernidad «como pura hybris e impiedad», donde se subvierten principios tradicionales en clave emancipadora, pero también de manera confusa y descontrolada: «Hybris es hoy toda nuestra actitud con respecto a la naturaleza, nuestra violentación de la misma con ayuda de las máquinas y de la tan irreflexiva inventiva de los técnicos e ingenieros» (GM, III, p. 9). Se ha puesto en marcha una fuerza - multiplicada por la técnica- que parece arrastrarnos como un nuevo y ciego instinto, pero 
sin que aún se haya corregido la inversión ascética de la voluntad de poder. En efecto, las ventajas materiales han engendrado otros espejismos. \&La gente vive para el hoy, vive con mucha prisa - vive irresponsablemente: justo a csto es a to que llaman "libertad", al punto de confundir toda autoridad institucional con esclavitud-» (CI, Incursiones de un intempestivo, p. 39). Semejante aturdimiento conduce a veces a la vida frivola, pero en muchas ocasiones prevalece el viejo mecanismo de la alienación y el vacio interior: «¿Qué destruye más rápidamente que trabajar, pensar, sentir sin necesidad interna, sin una elección profundamente personal, sin placer?, ¿como un autómata del "deber"?" (AC, p. 11). La despersonalización ha ganado la partida, más allá de ciertos cambios y mejoras, de tal modo que el proceso histórico de domesticación acaba en la más estrepitosa huida hacia la inconsistencia. Nuestra hipótesis en este punto es que puede rastrearse una relación entre la crítica nietzscheana a los «ideales ascéticos» y la crítica a la «cosificación» universal que veremos en Adorno, es decir, que aquéllos han ocasionado en buena medida ésta. Y sólo los francotiradores del aforismo exterior escapan a la inexorable lógica interna del sistema totalizante y autolegitimador.

Si estamos en lo cierto - y esto sólo es un esquema-, el proceso que va de la milenaria «ética de la costumbre» que contribuyó a crear al individuo autónomo y valorativo, responsable y consciente ( «capaz de prometer"), ha dado paso históricamente a un tipo de sujeto sometido a la actividad maquinal, a la dedicación absorbente a un hacer monótono (el trabajo), para embotarse y escapar del sufrimiento: «la actividad maquinal y lo que con ella se relaciona, como la regularidad absoluta, la obediencia puntual e irreflexiva, la adquisición de un modo de vida de una vez para siempre, el tener colmado el tiempo, una cierta autorización, más aún, una crianza para la "impersonalidad", para olvidarse a sí mismo, para la incuria sui: ide qué modo tan profundo y delicado ha sabido el sacerdote ascético utilizar estas cosas en la lucha contra el dolor!» (GM, III, p. 18, y antes, II, p. 2). El resultado de la interpretación del sufrimiento como «mala conciencia»y sentimiento de culpa arroja al ser humano a una extraña mezcla de narcosis $y$ exacerbación perversa de la vida, a un falso «mejoramiento». Lo que implica, a su vez, la cosificación de la verdadera voluntad de poder, invertida en forma de «sofocación global del sentimiento de vida, la actividad maquinal, la pequeña alegría, sobre todo la del "amor al prójimo", la organización gregaria, el despertamiento del sentimiento de poder de la comunidad...» a través del cual se sublima el hastío individual (GM. III, p. 19, y antes, p. 20). En todo ello hay ofuscación y sometimiento, maquillaje de los instintos (moralizados) y una repugnante «buena conciencia» que de la primera negación de sí pasa a una falsa autoafirmación adornada con espúreas gratificaciones. $\mathrm{Y}$, al final, cierto nihilismo mal disimulado, cansancio vital y huida hacia delante son el trasfondo de la cultura. Adorno radicalizará estas críticas con nuevos ingredientes y hará de su dialéctica negativa el contrapunto a la afirmativa actividad nietzscheana (antidialéctica), una vez que ésta fue cuestionada ( ¿contradicha, traicionada?) por la historia. 


\section{En relación a Adorno}

Pretendemos mostrar una vez más cómo la opción por el aforismo conlleva una posición filosófica de conjunto, ciñéndonos con la misma brevedad a lo que nos parece el núcleo del tema. Adorno introduce un enfoque distinto, marcado por la experiencia desgarradora sufrida en el siglo $\mathrm{xx}$, y su planteamiento inicial consiste en superar el movimiento identificador - homogeneizador- del pensamiento ( Pensar quiere decir identificar»), para resaltar el principio de contradicción que rige en la dialéctica, porque «dialéctica es la conciencia consecuentc de la diferencia» (lo negativo y divergente), en tanto fiel expresión de lo real; y por eso sirve a la «reconciliación» que significa tener presente la pluralidad que hoy rechaza la razón subjetiva ${ }^{7}$. Por consiguiente, hay que alejarse del concepto cosificado para llegar a lo "supraconceptual" de la realidad misma y así constatar que ael objeto de la experiencia espiritual es en sí un sistema antagónico» (DN, p. 18), pero sin renunciar para ello a la propia labor conceptual de la filosofía. Lo correcto es abrir el concepto a klo irracional», que en buena parte le constituye, mediante una autorreflexión crítica que todavía persigue una verdad objetiva: «En cuanto la conciencia entra en una cosa concreta y se expone a su pretensión inmanente de verdad o falsedad, se deshace la supuesta insustancialidad subjetiva del pensamienton, una vez que se postula la afinidad del cognoscente y lo conocido (DN, pp. 44, 50 ss., y antes, p. 21). Así, pues, Adorno comparte la crítica de Nietzsche al afán de sistema que elimina las «concreciones cualitativas» y reivindica un pensamiento que vea en las cosas más que lo «dado» como mera existencia (identidad), pero no suscribe el fenomenismo ni el ficcionalismo. Su alternativa se basa en impugnar por igual la totalización en forma de Absoluto metafísico ( «sistema deductivo de juicios sobre lo existente») y el modelo de «lo absolutamente distinto» e inasequible al pensamiento, para proponer una micrología que indaga en cada singularidad y luego las rcúnc en tanto «constelación legible de lo que existe (...) * configuración en la que compondrían una escritura» (DN, p. 405). Tarea difícil, sin duda, pues pretende una reforma desde dentro, una crítica severa pero sin rupturas...; en definitiva, un saber verdadero. $\mathrm{Y}$ es que sólo así puede servir a la intención política que su autor le da, crítica y emancipadora.

Y la manera de intentarlo es pensar lo especifico sin volatilizarlo en lo universal: 《a dialéctica negativa es un conjunto de análisis de modelos» cuyo escalón inferior o materia prima es la «inmersión en lo particular», pues «sólo una filosofía en forma de fragmentos realizaría de verdad las mónadas que el idealismo diseñó ilusoriamente. Serían imágenes de la totalidad, que como tal es irrepresentable en lo particulars (DN, p. 36). He aquí la formulación definitiva del proyecto filosófico de Adorno y el papel central del fragmento monadológico, que luego se articula en grupos de sentido mayor. Se trata de un pensamiento abierto que reniega tanto del absolutismo como del relativismo, que da más importancia a la trama de su mismo quehacer que a un fin que supuestamente la culmine, asumiendo los riesgos

T. W. Adorno, Dialéctica negativa, Madrid, Taurus, 1984 (reimp.), pp. 13 y 15, respect. En adelante citaremos por esta edición con la abreviatura $\mathrm{DN}$. 
de lo inseguro pero sin abandonar el rigor. Semejante desafio se plasma sobre todo en la obra que vamos a comentar a muy grandes rasgos, Minima Moralia, colección de aforismos que es su obra maestra, en palabras de Habermas, quien añade en otro lugar: "Adorno consideró el aforismo, centelleante en su evidencia, como la forma más adecuada de exposición, pues el aforismo como forma puede traer a lenguaje el secreto ideal de conocimiento que siempre abrigó Adorno, una idea que en el medio del habla argumentativa no puede expresarse o en todo caso no puede expresarse sin contradicción, a saber: que el conocimiento habría de romper la prisión del pensamiento discursivo y terminar en intuición pura»". Que el aforismo presente una evidencia intuitiva es discutible, claro está, pero ciertamente ahí se refleja su ambición de eficacia e impacto, con una expresión lingüística peculiar. En otras palabras, la autocrítica de la razón sólo puede realizarse - según Adorno- en forma de fragmentos que se correlacionan y contrastan (constelación, configuración), a la vez que desmiente cualquier jerarquización u ordenamiento global. Sólo así es posible que la conciencia entre en la cosa, según vimos más arriba, sin traicionarla. En resumen, la perspectiva filosófica adoptada no es holista ni atomista, sino relacional en sentido negativo: no hay síntesis ulterior.

En la Dedicatoria de Minima Moralia ${ }^{9}$ a Max Horkheimer se dice que esta «ciencia melancólica» (por contraste con la gaya ciencia nietzscheana) se ocupa del viejo tema de la "vida recta", pero cuyo sujeto hoy está históricamente sentenciado sin que haya nacido un tipo nuevo. Esta desaparición del sujeto obliga a una formulación en aforismos que no acata la vieja prohibición dialéctica contra lo aislado, e insiste -en oposición al proceder final de Hegel- en la negatividad. Si lo diferencial se repliega a la experiencia individual en esta época mercantil que lo despersonaliza todo, ahí deben buscarse «lugares de partida» y «modelos para el futuro esfuerzo del concepto». A pesar de la «complicidad» que hay en un discurso de/desde lo subjetivo, tal es el reducto provisional de la teoría crítica, que ahora «renuncia a la contextura teórica explícita» (ibid.). Por tanto, junto a la explicación interna al pensamiento que hallamos en Dialéctica negativa, aquí debe añadirse otra de carácter histórico para entender el texto fragmentario: la exposición crítica de una época que por su propia índole sólo es posible a través de trazos impresionistas múltiples (faena solidaria de otra gran obra, Dialéctica de la ilustración, precisamente subtitulada «Fragmentos filosóficos»). Por lo demás, se trata de encontrar slo esencial en lo marginal, en lo accesorio, el derecho que asiste a lo subversivo y expulsado, la verdad en la periferia y en lo inauténtico»; y ello expresado con la primacía de lo alegórico frente a lo simbólico, de la metonimia antes que la metáfora ${ }^{10}$. Así, en un estilo bien distinto del que vimos en Nietzsche, nos vamos a encontrar comentarios sobre escenas y gestos concretos de la vida colectiva; una galería de tipos humanos en su vertiente social; actitudes y comportamientos, observaciones sobre la cultura, el arte, el sexo, instituciones, hechos

' J. Habcrmas, Pensamiento postmetafisico, Madrid, Taurus, Humanidades, 1990, p. 259. La caracterización como obra maestra en Perfiles filosoficos-politicos, Madrid, Taurus, 1984, p. 146.

${ }^{\circ}$ Traducción de J. Chamorro Mielke, Madrid, Taurus, 1987. Citaremos por MM y los fragmentos por su númcro.

i" C. J. Habermas, El discurso filosófico de la modernidad, Madrid, Taurus, 1989, p. 227. 
actuales en ese momento como la guerra, etc. Y, sobre todo, contradicciones irresolubles, tensiones sin solución histórica a la vista. He aquí un boceto mínimo de ese quehacer fragmentario de la reflexión.

1. Un pensamiento improbable. La práctica de la filosofía también se halla atrapada en la red inextricable de un mundo asfixiante y alienador, por eso a duras penas puede ensayarse un pensar que intente cobrar distancia crítica. El conocimiento se da en «un entramado de prejuicios, intuiciones, inervaciones, autocorrecciones, anticipaciones y exageraciones» que nada tiene que ver con la transparencia lógica ni con la inmediatez de la intuición esencial, por lo que nunca puede autolegitimarse del todo (MM, p. 50). Es una materia hibrida e impura en continuo debatc consigo misma y con lo demás, sin referencias seguras de ninguna clase. Sólo «la visión de lo lejano, el odio a la banalidad, la búsqueda de lo aún no manido, de lo aún no captado por el esquema conceptual universal, constituyen la ültima posibilidad para el pensamiento» (MM, p. 41). Estilo, pues, explorador pero sin optimismo, ajeno a la academia y a la bohemia, desconfiado de todo asiento y de toda pose. Porque hay que comenzar por no autoafirmarse, es decir, por abandonar el «querer tener razón» como principio argumental, para abrirse a saberes «vulnerables» (no irracionales ni arbitrarios), donde tesis y argumento se funden y dan cuenta de sí: «Todos los conceptos-puente, todas las conexiones y operaciones lógicas secundarias y no basadas en la experiencia del objeto deben eliminarse. En un texto filosófico, todos los enunciados debieran estar a la misma distancia del centro» (MM, p. 44). Tal es la definición perfecta del aforismo dentro de una óptica horizontal (sin jerarquía lógica), en la que cada texto sólo apela a su propia fuerza para hacerse valer, y sin pretender imponerse ni cerrar la discusión. Por otro lado, la dialéctica no acepta la dicotomía racional/irracional, sanolenfermo, salvo para indagar lo segundo (lo desviado y dislocado) en tanto «germen de auténtica curación» que debe hacerse consciente como alternativa al falso "sano sentido común» (MM, p. 45), es decir, como reverso marginal del orden imperante. En este sentido, contra la tautología discursiva de la llamada razón pura hay que incluir -...en la estela de Nietzsche- los instintos y deseos, la memoria y la fantasía, las emociones..., todo aquello que humaniza frente a la acastración de la percepción» (MM, p. 79). Por eso debe buscarse en la contraposición de entendimiento y sentimiento «la unidad de ambos: una unidad moral. La inteligencia como facultad del juicio se opone en el acto de juzgar a lo dado al tiempo que lo expresa" (MM, p. 127), guiándose por un impulso que no cede a la esclavitud. Al fin y al cabo se trata de «poner todos los argumentos reaccionarios contra la cultura occidental al servicio de la ilustración progresista", de realizar la inversión (dialéctica) de la gran inversión de la libertad que existe, aunque sea en difíciles términos negativos: «Sólo son verdaderos los pensamientos que no se comprenden a sí mismos» (MM, p. 122).

En efecto, el empeño básico de «romper el carácter impositivo de la lógica con los medios de ésta» (a través de «lo vencido», de los desechos y "puntos ciegos», de lo anacrónico que escapa a las leyes del movimiento histórico), corre el riesgo de caer en ese mismo carácter por alguna "astucia de la razón» (MM, p. 98); en particular en lo que se refiere a las cuestiones prácticas de todo tipo. 
No es sólo el lamentable ejemplo del positivismo, el pragmatismo o el instrumentalismo, sino la más radical posición idealista que del primado de la razón práctica pasa a despreciar la teoría y a olvidar las buenas intenciones iniciales, como en Hegel; esa idolatría de los grandes sistemas especulativos por la «pura acción" que conduce a la violencia de conquista, en contraste con la mirada contemplativa donde «el impulso hacia el objeto queda detenido y sujeto a reflexión» porque el contemplador no se asimila al objeto (MM, pp. 53 y 54, respect.). La crítica se dirige, pues, hacia el vínculo subterráneo entre cierta forma de pensar y de actuar (p. ej., en Alemania), en tanto que pone en marcha procesos inexorables al modo de apisonadoras lógicas y prácticas. De ahí deriva también la falsa kesquematización de lo importante y lo accesoriom, cuando lo más lúcido sería una consideración "fragmentaria y excéntrica" de los grandes temas para escapar a esa trampa homologadora según la calidad del objeto, y hacer valer cl hecho de que «la autocrítica de la razón es su más auténtica moral» sin eliminar al sujeto; en otras palabras, el pensamiento debe distanciarse de la vida para mejor enraizarse en ella, sin erróneas confusiones ni mera reproducción del ser, distancia que es «el precipitado de la historia en los conceptos» y que también se expresa en el tono lúdico (ligero, fugaz) tan querido a Hegel y Nietzsche (MM, pp. 81 y 82, respect. Sobre el juego como contrapunto a lo real utilitario y como triunfo del valor de uso sobre el valor de cambio, véase p. 146). Sólo con estos puntos de fuga, con esas brcchas autocríticas, cautelosas a la par que relajantes, es posible un discurso descentrado y respetuoso, flexible y plural. A su vez plasmado en textos densos, trabados y transparentes, abiertos a la metáfora y a toda clase de materiales (excepto al exceso de citas), para irradiar desde sí hacia nuevos objetos de atención (MM, p. 51), a pesar de las irreductibles antinomias históricas del lenguaje (p. 141); y, sobre todo, textos atravesados de ironia, que es la diferencia entre la ideología y la realidad (MM, p. 134). De otro modo, «la socialización del espíritu tendrá a éste confinado, retenido, a recaudo mientras la sociedad misma continúe prisionera», engullido por el aparato económico y político (MM, p. 126). Es la triste situación que Adorno describe como «estupidez planetaria, a la que el mundo actual le impide ver el desatino de su propia instalación» (MM, p. 127), producto del interés y el dominio sin escrúpulos.

2. Sobre tipos y comportamientos. Contra la muy extendida inconsciencia y el conformismo - hoy, que parece casi de mal gusto clamar contra la injusticia-, Adorno traza agudas semblanzas de la vida deshumanizada en los pequeños gestos y actitudes cotidianas, además de los atropellos y conflictos más evidentes. Si partimos de que «el todo es lo no verdadero» (MM, p. 29), hemos de fijarnos en las escenas de la vida privada ( $p$. ej., el tipo de casas y la forma de habitarlas) que demandan independencia y desapego frente a las posesiones (p. 18), o en el efecto que produce un entorno de objetos utilitarios frente a los que no hay libertad: "Por ahora, la tecnificación hace a los gestos precisos y adustos, y con ellos, a los hombres. Desaloja de los ademanes toda demora, todo cuidado, toda civilidad para subordinarlos a las exigencias implacables y como ahistóricas de las cosas» (p. 19). Es el sutil maquinismo que se apodera de la conciencia como cstilo vital, la irracional racionalización de los comportamientos. $O$ el contraejemplo 
de la amabilidad que a veces con buenas intenciones enmascara la cruda realidad (pp. 5, 38), o el acto de regalar convertido en fría rutina mercantil (p. 21). No importa donde volvamos la vista, la cosificación de la existencia avanza sin cesar: sea por la cuantificación de todo, por la parodia del propio concepto de hombre, por el «sistema de funciones automatizadas» en la división del trabajo, el consumo indiscriminado donde los productos crean las necesidades, el uso técnico-estratégico de lo personal, la prisa y la pseudoactividad junto a las industrias del ocio para ocultar el vacío psicológico y la absorción colectiva de lo individual, sea por el imperio del "cotilleo" y la degradación de la conversación en monólogo defensivo o agresivo, etc. (cf. respect., pp. $25,68,75,76,85,90,91,115$ ). Adorno fija la mirada crítica sobre mil fragmentos de la vida social, aun a riesgo de parecer en exceso pesimista o suspicaz. Sin embargo, son tantos los casos para componer una miscelánea del sufrimiento y del abuso, de la patología hecha norma, que es dificil negar la evidencia. ¿O acaso los arquetipos imperantes de la salud y el sexo no son opresivos y delirantes (pp. 36, 40, 107, 139), vías para un nuevo control (medicalizado) de los sujetos y para su mera relación mecánica?, bo es que no hay una sofisticada producción social de la inversión entre verdad y mentira (pp. 9, 71), sin que apenas produzca escándalo ya?... por dar dos ejemplos significativos y disímiles. Es el triunfo de la ilusión aceptada, de la renuncia a una felicidad auténtica, la resignación ante las frías relaciones interpersonales..., la indiferencia y la abstracción que alcanzan incluso a una idea domesticada de la muerte (p. 148).

Si damos un giro hacia otro enfoque encontramos una descripción de tipos humanos representativos, igualmente articulada en forma de una «configuración» legible de la realidad: asi, el intelectual, desde diversas perspectivas que van del estupor a la complicidad (pp. 1, 13,83, 84, 132); o el hábil conocedor de los entresijos del sistema como nuevo profesional (p. 3); el filántropo acomodado e hipócrita (p. 4); el nuevo tipo de avaro en la sociedad del bienestar (p. 15); el «ascetismo» ignorante de los técnicos e investigadores (p. 80)... Y por lo que se refiere al estudio de situaciones varias desde una óptica sociológica: las trampas y posibilidades del amor, de la familia y el matrimonio (pp. 2, 10, 11, 49, 104, 111); la conciencia ingenua de una libertad inexistente y la falsa «autenticidad» de unos individuos cuyos aegos» en verdad son heterónomas relaciones objetivas que los despersonalizan (pp. 94, 99); la reglamentación del tiempo libre y del placer (p. 113); el sojuzgamiento de la mujer y los riesgos de una emancipación equivocada (p. 57); o las supersticiones sintomáticas de una alineación colectiva eл el ocultismo (p. 151)... No pretendemos abarcar lo que sólo puede ser una enunciación múltiple, como corresponde a la diversidad de asuntos y a la intención de los textos. Pero no es menos cierta la impresión de conjunto que produce, la conciencia desgarrada que alerta sobre una época. Lo interesante es que esta misma fragmentación es la que más contribuye a crear ese efecto acumulativo y coherente, incisivo y revelador, como el prisma que descompone la luz sin violentarla.

3. Por una dialéctica abierta. En la posición de Adorno hay un interês moral evidente que también hace de los pequeños actos de cada día la piedra de toque 
monadológica, además de ser el terreno adecuado para la máxima general de evitar la inmediatez: "Donde lo inmediato se afirma y parapeta se impone sombríamente la mala mediatez de la sociedad. Sólo una reflexión más precavida puede hacerse cargo de la inmediatez. Para eso prueba con lo más pequeño» (p. 116). Hasta aquí hay rasgos comunes con los otros autores, pero en seguida aparecen las dificultades que ya anunciamos al principio: la crítica se enreda con lo criticado, el pensador está amanchado» por la situación que vive y no hay alternativas positivas seguras; sólo -y precisamente por ello- una reflexión fragmentaria es posible. Sea en la crítica del poder y de la economía política, en el rechazo de la utopía que exige la unidad de teoría y praxis o en la degeneración del marxismo, los peligros de «contagio» son claros, hasta abocar a una situación paradójica: «frente a la mentira del mundo de la mercancia, la propia mentira se convierte en correctivo que denuncia a aquéls (p. 22). No puede regir el viejo afán de verdad en una situación esencialmente pervertida, sino sólo la insobornable aspiración a lo que no se agota en la cxistencia, a lo otro que nos anuncia el arte en el mejor caso: el caos en el orden, lo arbitrario en lo maquinal, «el arte es magia liberada de la mentira de ser verdad" (p. 143). No podemos detenernos en esa peculiar salida estética, opuesta a cualquier discurso totalizador dada su fragilidad también fragmentaria (p. 145) y de rasgos indefinidos. Más aún cuando la realidad presente se impone - según Adorno- con el "salto cualitativo" de sufrimiento y terror que expresan los campos nazis de exterminio, incomparable a desgracias históricas anteriores (p. 149). En efecto, no hay consuelos ni respuestas, sólo paradojas: la propia esperanza en un futuro mejor puede convertirse en coartada allí donde todo es contingencia y deformidad; la felicidad es una noción ambivalente mezclada siempre con «el inmenso dolor de lo existente»; la Ilustración es tan racional como irracional; lo condicionado afecta al propio anhelo de lo incondicionado; la filosofía negativa, en tanto disolvente universal, se disuelve a sí misma porque la dominación lo penetra todo, y la «perenne irreconciliabilidad de sujeto y objeto es el tema de la crítica dialéctica» (respecto., pp. $72,77,128,152,153$ ). No es posible renunciar al ansia de «redención», al salto hacia otras condiciones radicalmente diferentes, pero al cabo sólo se puede tener una consciencia más aguda de los antagonismos. Y los textos fragmentarios sirven una vez más para reflejar esa tensión, el choque de lineas de fuerza dispares, de síntomas e impulsos sin resolución final... Pero no queremos terminar este apresurado recorrido sin citar una ultima formulación de la incurable nostalgia por lo que no existe: «Así una voz nos dice, cuando esperamos la salvación, que la esperanza es vana, y sin embargo es ella sola, la impotente, la que nos permite dar un respiro. Toda contemplación no puede ya sino reproducir pacientemente la ambigüedad de la melancolía en nuevas figuras y aproximaciones. La verdad es inseparable de la ilusión de que alguna vez de las figuras de la apariencia surja, inaparente, la salvación» (p. 78). 


\section{Apéndice: fragmento y complejidad}

Para terminar, proponemos un breve bosquejo de lo que sería una teoría compleja de lo fragmentario. Hasta aquí se ha hablado de la íntima telación de la forma $y$ el fondo en el texto a través de ejemplos concretos que ponen de manifiesto cierto talante filosófico y una crítica global de la modernidad. Ahora se busca un modelo más abstracto de la mano del muy actual «paradigma ecológico y de complejidad» diseñado por Edgar Morin ${ }^{11}$; es decir, queremos aplicar algunas nociones de este nuevo método de conocimiento al texto fragmentario a título de simple ensayo inicial.

Partimos de las ideas de mosaico, constelación y mónada ya expuestas - ajenas por igual al holismo y al atomismo-, para afirmar la identidad compleja de lo uno y lo múltiple: la unidad crea diversidad y ésta genera unidad; las interrelaciones de las partes-textos constituyen una organización del todo-libro donde hay a la vez complementariedad, antagonismo y concurrencia, y donde cada fragmento tiene una doble identidad, la singular propia y su participación en el conjunto. Dicho con otras palabras, se da cierto «sistema abierto" (no un sistema reduccionista y jerarquizador) que evita la entropía - en analogía con los seres vivos-, por medio de la «relatividad, relacionalidad, diversidad, alteridad, duplicidad, incertidumbre» de los fragmentos que le constituyen. Así, los textos tejen y destejen redes de sentido entre sí, a la par que encarnan múltiples perspectivas abiertas hacia lo real, y tienen una doble contrastación mediante sus relaciones ecológicas internas y las del conjunto respecto al mundo extratextual. Hay, en efecto, coherencia, pero también desviaciones y diferencias, y es que los fragmentos se autoconstituyen con fuerza propia, pero también son producidos por sus interrelaciones (endo-exocausalidad) ${ }^{12}$. Hablamos entonces de «unitas multiplex imposible de simplificar y donde los vocablos forma-fondo remiten ahora a la «teoría de la Gestalt».

Desde otra óptica se puede entender el texto fragmentario como el evento singular o acontecimiento concreto que introduce desorden y azar en el orden predeterminado de los sistemas teóricos. Algo así como el accidente o choque dialéctico que desencadena nuevas ideas u observaciones, estableciendo una retroalimentación entre ambos planos e instancias. Frente al tradicional isomorfismo de ser y pensar, el aforismo es el punto de fuga de una reflexión autónoma, incluso deliberadamente ficcionalista. Es lo no clasificable, el símbolo, la metáfora o la imagen, el suceso puntual y certero que tensa y trastorna el cosmos de los grandes textos, pero también los regenera y enriquece. Por otro lado, el fragmento expresa con especial densidad metafórica las dimensiones que descubrimos en lo real: la fisica de las palabras, la biológica de los contenidos vivos y la antropo-social de

"Véase la tetralogía sobre El Método: I. La nuturaleza de la naturaleza; II. La vida de la vida: III. El conocimiento del conocimiento; IV. Las ideas, París, aparecidos en Editions du Scuil, 1977-1991 (traducción española en Fd. Cátedra, Madrid).

"z Hacemos una interpretación libre de conceptos aparecidos en La naturaleza de la naturaleza, Madrid, Cấtedra, 1981, pp. 141 ss., 173 ss., 305 ss. 
los sentidos y significados, esto es, la complejidad de lo que permanece y deviene en planos cualitativos irreductibles pero comunicados (ibid, pp. 414, 408). En definitiva, el texto como microcosmos y mónada, como novedad impredecible, como pensamiento libre y aventurero, nómada... que complementa, en el mismo acto en que lo desmiente, al sistema. 